\title{
Inhibition of mirtazapine metabolism by Ecstasy (MDMA) in isolated perfused rat liver model
}

\author{
Sanaz Jamshidfar, Yalda H. Ardakani, Hoda Lavasani and Mohammadreza Rouini
}

\begin{abstract}
Background: Nowadays MDMA (3,4-methylendioxymethamphetamine), known as ecstasy, is widely abused among the youth because of euphoria induction in acute exposure. However, abusers are predisposed to depression in chronic consumption of this illicit compound.

Mirtazapine (MRZ), an antidepressant agent, may be prescribed in MDMA-induced depression. MRZ is extensively metabolized in liver by CYP450 isoenzymes. 8-hydroxymirtazapine (8-OH) is mainly produced by CYP2D6. Ndesmethylmirtazapine (NDES) is generated by CYP3A4.

MDMA is also metabolized by the mentioned isoenzymes and demonstrates mechanism-based inhibition (MBI) in association with CYP2D6. Several studies revealed that MDMA showed inhibitory effects on CYP3A4.

In the present study, our aim was to evaluate the impact of MDMA on the metabolism of MRZ in liver.

Therefore, isolated perfused rat liver model was applied as our model of choice in this assessment.

Methods: The subjects of the study were categorized into two experimental groups. Rats in the control group received MRZ-containing Krebs-Henselit buffer $(1 \mu \mathrm{g} / \mathrm{ml})$. Rats in the treatment group received aqueous solution of $1 \mathrm{mg} / \mathrm{ml}$ MDMA (3 $\mathrm{mg} / \mathrm{kg}$ ) intraperitoneally 1 hour before receiving MRZ. Perfusate samples were analyzed by HPLC.

Results: Analyses of perfusate samples showed $80 \%$ increase in the parent drug concentrations and 50\% decrease in the concentrations of both metabolites in our treatment group compared to the control group. In the treatment group compared to the control group, $A \cup C_{(0-120)}$ of the parent drug demonstrated $50 \%$ increase and $\mathrm{AUC}_{(0-120)}$ of $8-\mathrm{OH}$ and NDES showed $70 \%$ and $60 \%$ decrease, respectively.

Observed decrease in metabolic ratios were $83 \%$ and $79 \%$ for $8-\mathrm{OH}$ and NDES in treatment group compared to control group, respectively.

Hepatic clearance $\left(C L_{h}\right)$ and intrinsic clearance $\left(C_{\text {int }}\right)$ showed 20\% and 60\% decrease in treatment group compared to control group.
\end{abstract}

Conclusion: All findings prove the inhibitory effects of ecstasy on both CYP2D6 and CYP3A4 hepatic isoenzymes.

In conclusion, this study is the first investigation of MRZ metabolism in presence of MDMA in isolated perfused rat liver model.

Keywords: Mirtazapine, Ecstasy, Metabolism, Isolated perfused rat liver model

\footnotetext{
*Correspondence: rouini@tums.ac.ir

Biopharmaceutics and Pharmacokinetic Division, Department of

Pharmaceutics, Faculty of Pharmacy, Tehran University of Medical Sciences,

Tehran, Iran
} 


\section{Background}

Nowadays, hallucinogens and stimulants are profoundly abused by the youth due to their primary effects to elevate energy levels, to induce euphoria, and to reach higher levels of pleasure and empathy. MDMA (3,4methylenedioxymethamphetamine), known as ecstasy, is one of these illicit drugs that acts as both releaser and reuptake inhibitor of central neurotransmitters and causes a large number of adverse effects not only in acute encounter but also in long-term abuse [1].

Major metabolic pathways involved in the bioactivation of MDMA are N-dealkylation and O-demethylenation. Ndealkylation of MDMA, catalyzed by CYP2B6, CYP1A2, and CYP2C19, produces the metabolite 3,4-methylendioxyamphetamine (MDA). O-demethylenation of MDMA and MDA, mediated by CYP2D6, CYP3A4, and CYP2C19, produces 3,4-dihydroxymethamphetamine (HHMA) and 3,4-dihydroxyamphetamine (HHA), respectively. HHMA and HHA metabolism generates 4-hydroxy-3-methoxymethamphetamine (HMMA) and 4-hydroxy-3-methoxyamphetamine (HMA) by the activity of catechol-Omethyltransferase (COMT) [2, 3].

MDMA demonstrates non-linear pharmacokinetics; the non-linearity is due to mechanism-based inhibition (MBI), observed in chemical structures containing methylendioxy group $[1,4]$. Previous studies revealed that MDMA exhibited MBI in association with CYP2D6 isoenzyme. It is hypothesized that CYP2D6 forms an orthoquinone intermediate with methylendioxyphenyl ring of MDMA. This complex attacks macromolecular structures as a nucleophile and interferes with their functions $[4,5]$. These events result in irreversible inhibition of CYP2D6 isoenzyme, which resembles CYP2D6 inhibition by paroxetine $[4,6]$. This phenomenon involves most of CYP2D6 isoenzymes and is demonstrated within $1 \mathrm{~h}$ of MDMA administration [7].

Chronic abuse of MDMA is associated with a wide variety of complications such as serotonergic and dopaminergic nerve deterioration, cognitive disorders, and psychological problems [8]. Among these adverse effects, depression is one of the most common psychiatric problems associated with long-term consumption of ecstasy. Treatment of MDMA-induced depression is, therefore, of great value.

Mirtazapine (MRZ), a piperazinoazepine compound, belongs to noradrenergic and specific serotonergic antidepressants (NaSSA) [9]. Its pharmacological activity is virtually associated with presynaptic- $\alpha 2$ receptor blockade, which results in an increase in both serotonin and norepinephrine levels and contributes to antidepressant activities [10]. In clinical practice, MRZ is particularly indicated for treatment of major depressive disorder (MDD) [11].
Previous clinical studies have shown that MRZ is superior to placebo and some selective serotonin reuptake inhibitors (SSRIs) such as fluoxetine. MRZ also has equal efficacy as some tricyclic antidepressants (TCAs) such as amitriptyline and clomipramine in treatment of depression. Moreover, MRZ is better tolerated during the treatment process since it does not induce nausea and has less anticholinergic side effects. MRZ exhibits more rapid onset of action compared with TCAs and SSRIs [11].

MRZ demonstrates linear pharmacokinetics in the therapeutic dosage regimen (15 to $80 \mathrm{mg} /$ day). Good absorption via oral route and elimination half-life of 20 to $40 \mathrm{~h}$, that is in favor of once daily dosing, are of notable pharmacokinetic parameters of MRZ [12].

MRZ is mostly excreted in urine and is extensively metabolized in liver by means of CYP450 isoenzymes. CYP3A4, CYP2D6 and CYP1A2 are involved in biotransformation of MRZ. 8-hydroxymirtazapine (8-OH), the major metabolite, is mainly produced by CYP2D6 and to a lesser extent by CYP1A2. N-desmethylmirtazapine (NDES), the only pharmacologically active metabolite, and $\mathrm{N}$-oxidemirtazapine are generated by CYP3A4 $[13,14]$.

In this study we focused on the possible interaction between MRZ and MDMA, considering both CYP2D6 and CYP3A4 isoenzymes. We assessed the impact of MDMA on the metabolism of MRZ in liver. Therefore, isolated perfused rat liver model was applied as our model of choice in this assessment.

\section{Materials and methods Materials}

MRZ, 8-OH and NDES were kindly supplied by Mario Georgi (University of Pisa, Italy).

MDMA.HCl powder was synthesized in Medicinal Chemistry Department of Tehran University of Medical Sciences according to the previously reported [15] method that showed the acceptable purity compared to standard sample purchased from Lipomed Pharmaceutical (Switzerland). The structure was confirmed by IR, H-NMR and Mass spectra.

HPLC grade acetonitril and methanol, and analytical grade salts such as potassium dihydrogen phosphate were all from Merck (Darmstadt, Germany).

\section{Standard solutions}

Primary stocks of MRZ and its two major metabolites were prepared by dissolving pure powders in methanol to make concentration of $1 \mathrm{mg} / \mathrm{ml}$. Final dilution for QC and calibration samples was done using Krebs-Henselit buffer. MRZ and NDES concentrations were between 5 and $150 \mathrm{ng} / \mathrm{ml}$. Concentrations used for $8-\mathrm{OH}$ were between 2.5 and $75 \mathrm{ng} / \mathrm{ml}$ (Fig. 1). All the above solutions 


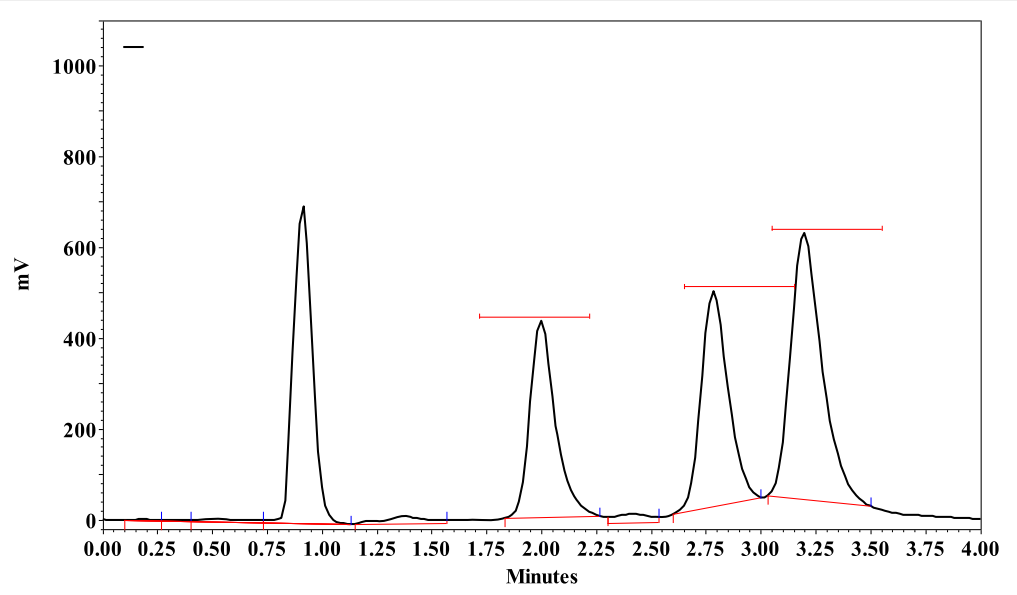

Fig. 1 Chromatogram of standard solution ( $40 \mathrm{ng} / \mathrm{ml}$ of $8 \mathrm{OH}$ and $80 \mathrm{ng} / \mathrm{ml}$ of NDES and MRZ). Retention time:(8-OH: 2 min, NDES: $2.75 \mathrm{~min}$, MRZ: $3.25 \mathrm{~min}$ )

were kept at $4{ }^{\circ} \mathrm{C}$. Aqueous stock of MDMA $(1 \mathrm{mg} / \mathrm{ml})$ was prepared by dissolving in double distilled water.

\section{Animals}

Twelve healthy male Sprague-Dawley rats (divided into two experimental groups called control and treatment) weighting between 250 and $300 \mathrm{~g}$ were applied in this assessment. They were kept under 12-h lightdark cycle with controlled environment temperature and without any limit in access to standard laboratory chow and water.

The present study was approved by the Institutional Review Board of Tehran University of Medical Sciences. Ethical approval code number was [253066].

\section{Rat liver perfusion}

The rats were anesthetized via intraperitoneal (IP) injection of xylazine/ketamine mixture (15/75 mg/ $\mathrm{kg})$. Cannulation of portal vein and inferior vena cava was done using previously heparinized intravenous catheters (guage of 16, 18 respectively). After inserting catheters, the Krebs-Henselit buffer (118 mM NaCl, $4.5 \mathrm{mM} \mathrm{KCl,2.75} \mathrm{mM} \mathrm{CaCl}_{2}$, $1.19 \mathrm{mM} \mathrm{KH} \mathrm{PO}_{4}, 1.18 \mathrm{mM} \mathrm{MgSO}$, and $25 \mathrm{mM}$ $\mathrm{NaHCO}_{3}$ ) adjusted to the physiological $\mathrm{pH}$ (using $95 \% \mathrm{O}_{2} / 5 \% \mathrm{CO}_{2}$ ) was passed through the portal vein employing peristaltic pump set on the constant flow rate of $500 \mathrm{ml} / \mathrm{h}$ for $10 \mathrm{~min}$. Then MRZ-containing medium (inlet concentration of $1 \mu \mathrm{g} / \mathrm{ml}$ ) was delivered into the portal vein for $120 \mathrm{~min}$ and the perfusate samples were collected immediately after wash and then every $10 \mathrm{~min}$ from the inferior vena cava to calculate outlet concentrations of parent drug and both metabolites.

Earlier rat liver perfusion studies with MRZ in our lab revealed that $8-\mathrm{OH}$ metabolite of $\mathrm{MRZ}$ was not detectable in low parent drug concentrations while NDES was measurable even in low concentrations of MRZ, so, a $1 \mu \mathrm{g} / \mathrm{ml}$ concentration of MRZ was selected as exposure concentration for control $(n=6)$ and treatment $(n=6)$ group.

Previous studies showed that single dose administration of MDMA ( $3 \mathrm{mg} / \mathrm{kg}$ ) to rats resembles the plasma concentration following the ordinary MDMA dosage taken in humans [16].

So, treatment group were received freshly prepared aqueous solution of $1 \mathrm{mg} / \mathrm{ml}$ MDMA ( $3 \mathrm{mg} / \mathrm{kg}$ ) intraperitoneally 1 hour before receiving MRZ-containing medium $(1 \mu \mathrm{g} / \mathrm{ml})$ through the single pass mode of liver perfusion.

Perfusion pressure $(15 \mathrm{mmHg})$, temperature, and $\mathrm{pH}$ (7.4) were monitored continuously during the procedure and remained constant till the end. Liver viability tests were carried out intermittently and were passed. Normal range for AST and ALT are $0-46(\mathrm{U} / \mathrm{L})$ and $0-49(\mathrm{U} / \mathrm{L})$ respectively (Figs. 2 and 3 ).

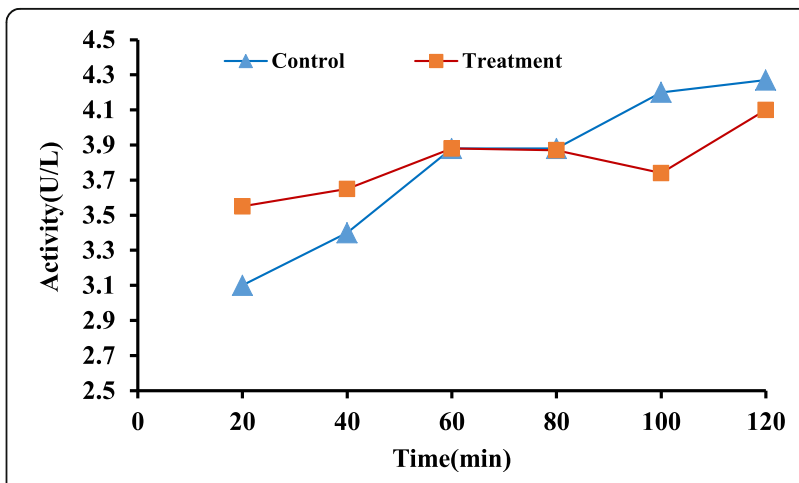

Fig. 2 Mean profile of AST during the perfusion study in control and treatment groups $(n=6)$ 


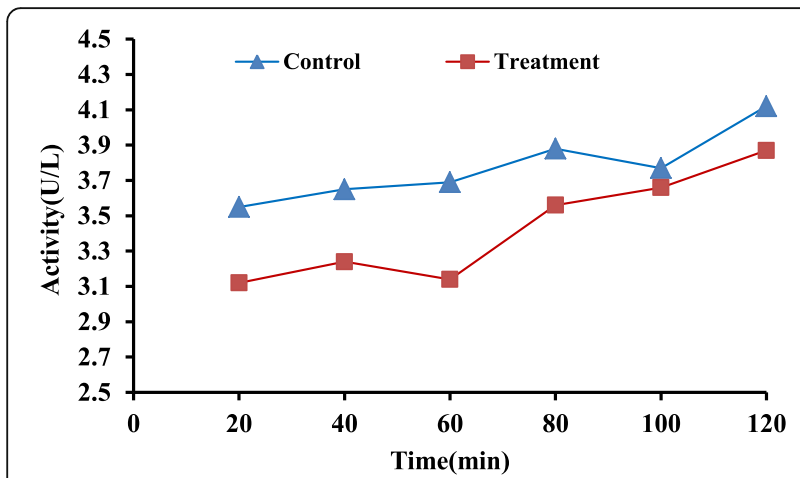

Fig. 3 Mean profile of ALT during the perfusion study in control and treatment groups $(n=6)$

Collected samples (in $10 \mathrm{~min}$ intervals) were centrifuged for $15 \mathrm{~min}$ at $12000 \mathrm{rpm}$ and the clear solutions were separated and were stored at $-20{ }^{\circ} \mathrm{C}$ until use.

\section{Apparatus and chromatographic condition}

The chromatographic apparatus consisted of a low pressure gradient HPLC pump coupled with fluorescence detector $(290 \mathrm{~nm}-370 \mathrm{~nm})$, a $100 \mu$ lit loop, and a Rheodyne model $7725 \mathrm{i}$ injector, all from Knauer (Berlin, Germany).

A Chromolith" ${ }^{\mathrm{Tm}}$ Performance RP-8e $100 \mathrm{~mm} \times 4.6$ column (Knauer, Berlin, Germany) attached to a protective Chromolith $^{\text {Tw }}$ guard cartridge RP-18e $5 \mathrm{~mm} \times 4.6 \mathrm{~mm}$ was applied for chromatographic separation (Merck, Darmstadt, Germany).

A mixture of $0.025 \mathrm{M} \mathrm{KH}_{2} \mathrm{PO}_{4}$ buffer, adjusted to $\mathrm{pH}=3$ using ortho-phosphoric acid, and acetonitril $(83: 17, v / v)$ was employed as mobile phase and was delivered through the column with the constant flow rate of $2 \mathrm{ml} / \mathrm{min}$ [17]. Data acquisition and analyses were achieved by ChromGate chromatography software (Knauer, Berlin, Germany).

\section{Pharmacokinetic parameters}

The analytes concentrations were determined using standard calibration curves. Based on concentrations of MRZ and its two metabolites, the areas under the concentration versus time curves AUC ${ }_{(0-120)}$ were acquired using trapezoidal rule. The metabolic ratios at different times for both metabolites were calculated using metabolite concentration divided by MRZ concentration at specific times.

Availability $(\mathrm{F})$, extraction ratio $(\mathrm{E})$, clearance $\left(\mathrm{CL}_{\mathrm{h}}\right)$ and intrinsic clearance $\left(\mathrm{CL}_{\text {int }}\right)$ were of hepatic pharmacokinetic parameters determined in this study using following equations [18].
$\mathrm{F}=\frac{\text { mean outlet concentration of MRZ at four latest samples }}{\text { inlet concentration of MRZ }}$

$$
\begin{aligned}
& \mathrm{E}=1-\mathrm{F} \\
& \mathrm{CL}_{\mathrm{h}}=\mathrm{Q} \times \mathrm{E} \\
& \mathrm{CL}_{\text {int }}=\mathrm{E} \times \frac{\mathrm{Q}}{\mathrm{F}}
\end{aligned}
$$

$\mathrm{Q}$, in the above equation, is the constant perfusion flow rate of $500 \mathrm{ml} / \mathrm{h}$ that equals $8.3 \mathrm{ml} / \mathrm{min}$.

Since concentrations of MRZ and its two metabolites reach the plateau at four latest time intervals, mean concentration of these samples were used in the equation.

All data in this study were reported as Mean \pm SD.

\section{Statistics}

The t-test was applied in this study in order to determine differences between means of groups $(P$ value $<0.05)$.

\section{Results}

According to our results, analyses of four latest sample intervals taken from treatment group showed $80 \%$ enhancement in parent drug concentration $(236.8 \pm 44.7$ vs $131.9 \pm 56.9 \mathrm{ng} / \mathrm{ml}$ ) in comparison to control group $(P$ value $<0.05)$ (Fig. 4$)$.

Similarly, the AUC ${ }_{(0-120)}$ of parent compound also showed 50\% enhancement in treatment group comparing to control group (1792.5 \pm 2871.7 vs $1184.8 \pm 3655.2$ ng.min $/ \mathrm{ml}),(P$ value < 0.05$)($ Table 1$)$.

Contrary to parent drug, concentrations of both metabolites, 8-OH and NDES, showed 50\% decrease in treatment group at four latest sampling time intervals compared to control group $(4.7 \pm 2.9$ vs $10.3 \pm 3.2 \mathrm{ng} / \mathrm{ml})$ and $(98.5 \pm 64.3$ vs $188.6 \pm 63.44 \mathrm{ng} / \mathrm{ml}),(P$ value $<0.05)$ respectively (Figs. 5, 6 and 7).

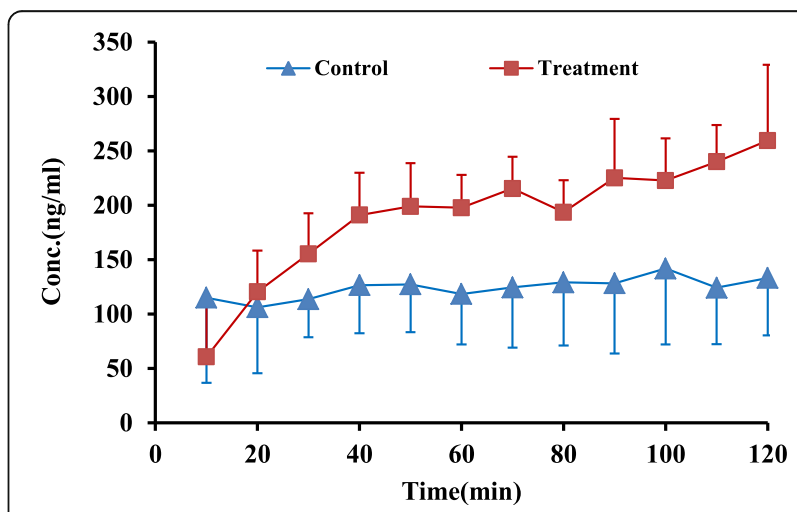

Fig. 4 Mean MRZ concentration $( \pm S D)$ vs. time in control and treatment groups $(n=6)$ 
Table 1 AUC $_{(0-120)}$ MRZ, NDES, and 8-OH in control and treatment groups $(n=6)$

\begin{tabular}{|c|c|c|c|c|c|c|}
\hline \multirow{2}{*}{ 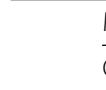 } & \multicolumn{2}{|l|}{ MRZ } & \multicolumn{2}{|l|}{$8-\mathrm{OH}$} & \multicolumn{2}{|l|}{ NDES } \\
\hline & Control & Treatment & Control & Treatment & Control & Treatment \\
\hline 1 & $15,530.1$ & $24,053.4$ & 2124.9 & 287.5 & $28,525.2$ & 593.7 \\
\hline 2 & 9928.7 & $18,031.1$ & 1398.9 & 398.6 & $22,505.4$ & $12,111.8$ \\
\hline 3 & $16,443.6$ & $17,675.6$ & 1960.2 & 449.2 & $15,171.6$ & $15,346.2$ \\
\hline 4 & $10,611.4$ & $23,553.7$ & 1674.1 & 415.4 & $18,839.8$ & 5860.1 \\
\hline 5 & $13,295.1$ & $23,063.4$ & 610.9 & 371.3 & $11,195.2$ & $10,613.3$ \\
\hline 6 & $19,497.1$ & $22,680.5$ & 588.2 & 920.5 & $12,075.7$ & 3605.2 \\
\hline MEAN & $14,217.7$ & $21,509.6^{*}$ & 1392.9 & $473.7^{*}$ & $18,052.1$ & $8021.7^{*}$ \\
\hline SD & 3655.2 & 2871.7 & 662.7 & 225.6 & 6650.9 & 5593.7 \\
\hline CV & 25.7 & 13.4 & 47.6 & 47.6 & 36.8 & 69.7 \\
\hline
\end{tabular}

${ }^{*} P$ value $<0.05$, significant difference between control and treatment groups

In accordance with decreasing in both metabolite concentrations in perfusate buffer at four latest sampling time intervals, the AUC ${ }_{(0-120)}$ of both metabolites showed 70\% and $60 \%$ decrease for $8-\mathrm{OH}$ and NDES respectively in treatment group in comparison to control group (473.7 \pm 225.6 vs $1392.9 \pm 662.7 \mathrm{ng} . \mathrm{min} / \mathrm{ml})$ and $(8021.7 \pm 5593.7$ vs $18,052.1 \pm 6650.8 \mathrm{ng} \cdot \mathrm{min} / \mathrm{ml}),(P$ value $<0.05)$ respectively (Table 1).

Based on pharmacokinetic equations, $\mathrm{CL}_{\mathrm{h}}$ and $\mathrm{CL}_{\mathrm{int}}$ demonstrated $20 \%$ and $60 \%$ decrease respectively in treatment group compared to control group $(6.3 \pm 0.4 \mathrm{vs} 7.2 \pm 0.5 \mathrm{ml} / \mathrm{min})$ and $(27.7 \pm 6.3$ vs $63.4 \pm 25.8 \mathrm{ml} / \mathrm{min}),(P$ value $<0.05)$, respectively (Table 2).

Metabolic ratios for 8-OH, main metabolite of CYP2D6, and NDES, main metabolite of CYP3A4, at four latest sampling time intervals showed $83 \%$ and $79 \%$ decrease respectively in treatment group compared to control group $(0.02 \pm 0.008$ vs $0.1 \pm 0.05)$ and $(0.45 \pm 0.3$ vs $1.7 \pm 0.8)$, ( $P$ value $<0.05)$, respectively (Figs. 8 and 9).

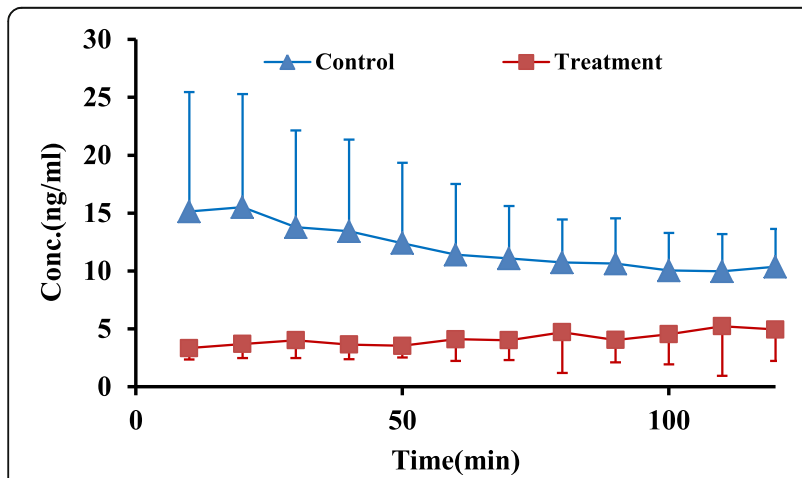

Fig. 5 Mean $8-\mathrm{OH}$ concentration $( \pm \mathrm{SD})$ vs. time in control and treatment groups $(n=6)$

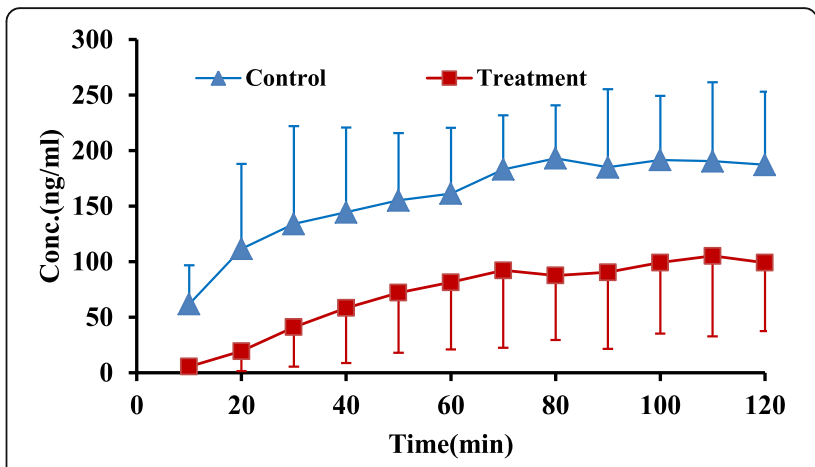

Fig. 6 Mean NDES concentration $( \pm S D)$ vs. time in control and treatment groups $(n=6)$

\section{Discussion}

Hepatic metabolism appears to play an important role in the toxicity induced by MDMA consumption [19]. MDMA is metabolized by various cytochrome P450 enzymes. The primary pathway is $\mathrm{O}$-demethylenation by CYP2D6; however, it has been shown that CYP3A4 is effectively involved in bioactivation of MDMA. Although several studies were focused on MDMA as a potent mechanism-based inhibitor of CYP2D6, a number of investigations proposed that inhibitory effects of MDMA on CYP3A4 could also be of great clinical value [20, 21].

Since both CYP3A4 and CYP2D6 are involved in many drugs metabolism, simultaneous use of MDMA and other substances could be of high concern.

In order to extend the desirable effects and cut down the undesirable ones such as depression or anxiety, most ecstasy users are interested in using other pharmaceutical drugs concurrently.

Previous studies have focused mostly on the pharmacodynamic interactions between MDMA, on one hand, and SSRIs and MAO inhibitors, on the other hand.

In a clinical study, after pretreatment of subjects with $20 \mathrm{mg} /$ day of paroxetine (a potent inhibitor of CYP2D6 and an SSRI) for 3 days before MDMA administration,

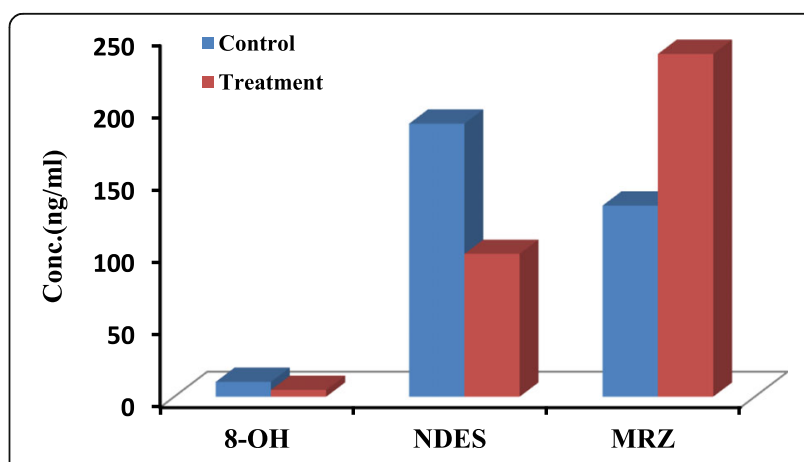

Fig. 7 Comparative histogram of MRZ, NDES and 8-OH concentrations at four latest samples in control and treatment groups $(n=6)$ 
Table 2 Comparison of availability, extarction ratio, clearance and intrinsic clearance $( \pm \mathrm{SD})$ in control and treatment groups $(n=6)$

\begin{tabular}{lllll}
\hline & $F$ & $E$ & $C L_{h}(\mathrm{ml} / \mathrm{min})$ & $C L_{\text {int }}(\mathrm{ml} / \mathrm{min})$ \\
\hline Control & $0.13 \pm 0.06$ & $0.87 \pm 0.06$ & $7.21 \pm 0.47$ & $63.4 \pm 25.81$ \\
Treatment & $0.24 \pm 0.04$ & $0.76 \pm 0.06$ & $6.33 \pm 0.37$ & $27.71 \pm 6.26$ \\
$P$ value & 0.005 & 0.004 & 0.005 & 0.008 \\
\hline
\end{tabular}

thirty hundred percent enhancement in MDMA plasma concentrations was observed. In spite of this concentration enhancement, psychological effects of MDMA were attenuated due to pharmacodynamic interactions [22].

Co-administration of moclobemide (a selective MAO A inhibitor) and MDMA caused several reported deaths due to serotonin syndrome [23].

MRZ can be prescribed in MDMA-induced depression [24]. Moreover, MDMA may be abused in patients suffering from depression who are under treatment with MRZ as a mood elevator [25]. The present study was, therefore, proposed to evaluate the pharmacokinetics of MRZ and its two main metabolites after MDMA administration.

As recent studies revealed that MBI could occur shortly after a single dose administration of MDMA, 1hour interval was chosen between rat IP injection of MDMA and exposure of liver to MRZ.

Our findings prove the inhibitory effects of MDMA not only on CYP2D6 but also on CYP3A4 hepatic isoenzymes.

Although the inhibitory mechanism of MDMA on CYP2D6 is known as MBI, the mechanisms that have been proposed to justify the inhibitory effects of ecstasy intake on other CYPs include increased levels of neurotransmitters, impairment of mitochondrial function, oxidation of biogenic amines, and metabolic bioactivation. Among these, it has been shown that biotransformation of MDMA has a significant role in its

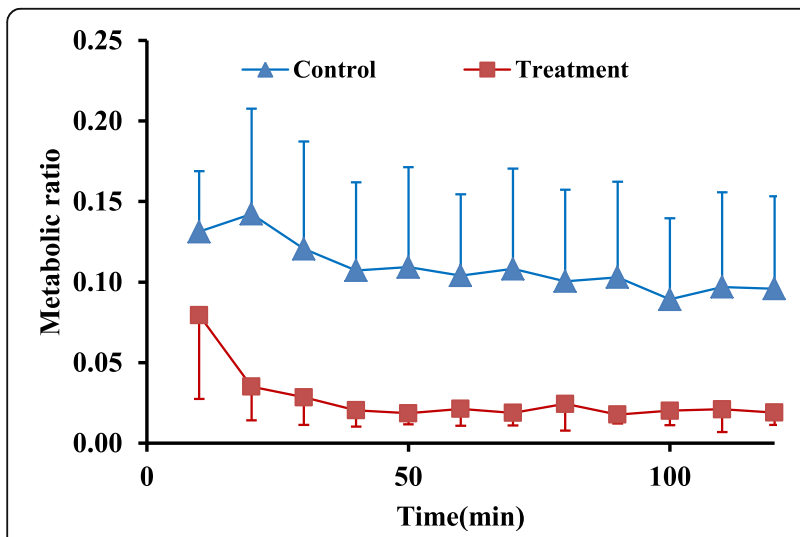

Fig. 8 Mean metabolic ratio of $8-\mathrm{OH}( \pm S D)$ at different time intervals in treatment and control groups $(n=6)$

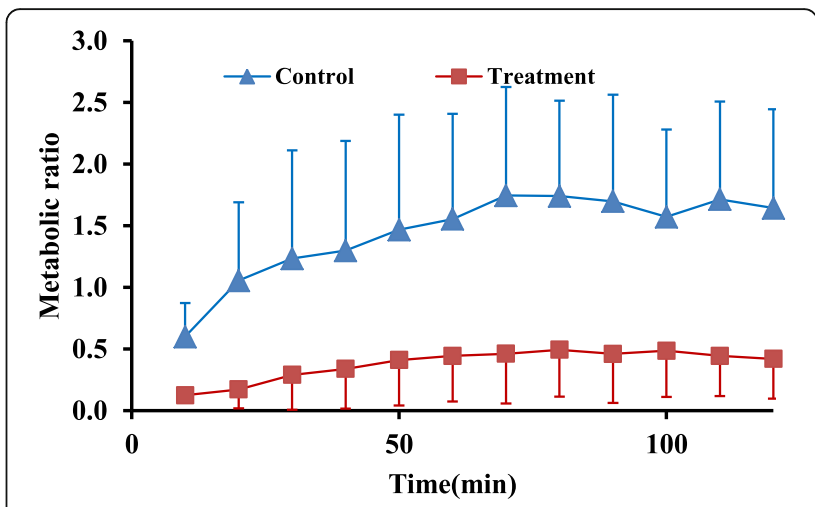

Fig. 9 Mean metabolic ratio of NDES $( \pm S D)$ at different time intervals in control and treatment groups $(n=6)$

hepatotoxicity because of its oxidative metabolites corresponding to the formation of ortho-quinones. These ortho-quinone compounds are able to enter a redox cycle that has been proposed to be the reason of cytotoxicity in several tissues such as liver, brain, kidney, and heart [2, 5-7, 20, 21, 26].

While several studies have focused on the interaction of MDMA with CYP2D6, the interaction of MDMA with CYP3A4 would also be of great clinical relevance because of the potential hepatotoxicity in MDMA abusers, which results from the reaction between oxidative metabolites and other essential intracellular macromolecules.

Another finding of this study, i.e., $80 \%$ enhancement in outlet perfusate concentration of MRZ in treatment group in comparison to control group, may propose the importance of dose adjustment in clinic. This finding is in line with two case reports [27] concerning the interactions between MRZ and fluvoxamine (an inhibitor of both CYP2D6 and CYP3A4 isoenzymes), that had reported 3 to 4 fold increase in serum concentrations of MRZ manifested by increased anxiety in patients under treatment [28].

\section{Conclusion}

In conclusion, this study is the first investigation of the metabolism of MRZ in presence of MDMA in isolated perfused rat liver model. To our knowledge, only few studies have been carried out on this subject. Complementary studies with higher amounts of MDMA or with different time intervals between IP injection of MDMA and liver perfusion are suggested to be designed.

\section{Abbreviations}

8-OH: 8-hydroxymirtazapine; COMT: Catechol-O-methyltransferase; HHA: 3, 4dihydroxyamphetamine; HHMA: 3, 4-dihydroxymethamphetamine; HMA: 4hydroxy-3-methoxyamphetamine; HMMA: 4-hydroxy-3methoxymethamphetamine; MBI: Mechanism-based inhibition; MDA: 3, 4methylendioxyamphetamine; MDMA: 3, 4methylenedioxymethamphetamine; MRZ: Mirtazapine; NDES: Ndesmethylmirtazapine 


\section{Acknowledgements}

Not applicable.

\section{Funding}

No funding was received.

\section{Availability of data and materials}

The datasets used and/or analysed during the current study available from the corresponding author on reasonable request.

\section{Authors' contributions}

MR R participated in research design. SJ conducted the experiments. $\mathrm{HL}$ contributed new reagents or analytical tools. YH A performed data analysis. Both SJ and YH A wrote or contributed to the writing of the manuscript. All authors read and approved the final manuscript.

\section{Competing interests}

The authors declare that they have no competing interests.

\section{Consent for publication}

Not applicable.

\section{Ethics approval and consent to participate}

The present study was approved by the Institutional Review Board of Tehran University of Medical Sciences. Ethical approval code number was [253066].

Received: 7 February 2017 Accepted: 12 June 2017

Published online: 28 June 2017

\section{References}

1. De la Torre R, Farré M, Roset PN, Pizarro N, Abanades S, Segura M, et al. Human pharmacology of MDMA: pharmacokinetics, metabolism, and disposition. Ther Drug Monit. 2004;26(2):137-44.

2. Antolino-Lobo I, Meulenbelt J, Nijmeijer SM, Scherpenisse P, van den Berg $M$, van Duursen MB. Differential roles of phase I and phase II enzymes in 3, 4-methylendioxymethamphetamine-induced cytotoxicity. Drug Metab Dispos. 2010:38(7):1105-12.

3. Jamali B, Ardakani YH, Foroumadi A, Kobarfard F, Rouini M-R. Determination of MDMA and Its Three Metabolites in the Rat Perfused Liver. J Anal Toxicol. 2013

4. Bertelsen KM, Venkatakrishnan K, Von Moltke LL, Obach RS, Greenblatt DJ. Apparent mechanism-based inhibition of human CYP2D6 in vitro by paroxetine: comparison with fluoxetine and quinidine. Drug Metab Dispos. 2003:31(3):289-93.

5. Heydari A, Yeo KR, Lennard M, Ellis SW, Tucker G, Rostami-Hodjegan A. Mechanism-based inactivation of CYP2D6 by methylenedioxymethamphetamine. Drug Metab Dispos. 2004;32(11):1213-7.

6. Venkatakrishnan K, Obach R, Rostami-Hodjegan A. Mechanism-based inactivation of human cytochrome P450 enzymes: strategies for diagnosis and drug-drug interaction risk assessment. Xenobiotica. 2007:37(10-11): 1225-56.

7. Yang J, Jamei $\mathrm{M}$, Heydari $\mathrm{A}$, Yeo KR, de la Torre R, Farré $\mathrm{M}$, et al. Implications of mechanism-based inhibition of CYP2D6 for the pharmacokinetics and toxicity of MDMA. J Psychopharmacol. 2006;20(6):842-9.

8. Green AR, Mechan AO, Elliott JM, O'Shea E, Colado MI. The pharmacology and clinical pharmacology of 3, 4-methylenedioxymethamphetamine (MDMA,"ecstasy"). Pharmacol Rev. 2003;55(3):463-508.

9. Delbressine L, Moonen M, Kaspersen F, Wagenaars G, Jacobs P, Timmer C, et al. Pharmacokinetics and biotransformation of mirtazapine in human volunteers. Clin Drug investig. 1998;15(1):45-55.

10. Puzantian T. Mirtazapine, an antidepressant. Am J Health Syst Pharm. 1998; 55(1):44-9.

11. Kasper S, Praschak-Rieder N, Tauscher J, Wolf R. A risk-benefit assessment of mirtazapine in the treatment of depression. Drug Saf. 1997;17(4):251-64.

12. Anttila SA, Leinonen EV. A review of the pharmacological and clinical profile of mirtazapine. CNS Drug Rev. 2001:7(3):249-64.

13. Störmer E, von Moltke LL, Shader RI, Greenblatt DJ. Metabolism of the antidepressant mirtazapine in vitro: contribution of cytochromes P-450 1A2, 2D6, and 3A4. Drug Metab Dispos. 2000;28(10):1168-75.

14. Timmer CJ, Sitsen JA, Delbressine LP. Clinical pharmacokinetics of mirtazapine. Clin Pharmacokinet. 2000;38(6):461-74.
15. Pizarro N, de la Torre R, Farré M, Segura J, Llebaria A, Joglar J. Synthesis and capillary electrophoretic analysis of enantiomerically enriched reference standards of MDMA and its main metabolites. Bioorg Med Chem. 2002; 10(4):1085-92

16. Baumann MH, Zolkowska D, Kim I, Scheidweiler KB, Rothman RB, Huestis MA. Effects of dose and route of administration on pharmacokinetics of $( \pm)-3,4$-methylenedioxymethamphetamine in the rat. Drug Metab Dispos. 2009;37(11):2163-70.

17. Lavasani H, Giorgi M, Sheikholeslami B, Hedayati M, Rouini MR. A rapid and sensitive hplc-fluorescence method for determination of mirtazapine and its two major metabolites in human plasma. Iran J Pharm Res. 2014:13(3):853.

18. Mehvar R, Vuppugalla R. Hepatic disposition of the cytochrome P450 2E1 marker chlorzoxazone and its hydroxylated metabolite in isolated perfused rat livers. J Pharm Sci. 2006;95(7):1414-24.

19. Downey C, Daly F, O'Boyle K. An in vitro approach to assessing a potential drug interaction between MDMA (ecstasy) and caffeine. Toxicol in Vitro. 2014;28(2):231-9.

20. Antolino-Lobo I, Meulenbelt J, Nijmeijer SM, Maas-Bakker RF, Meijerman I, van den Berg M, et al. 3, 4-Methylenedioxymethamphetamine (MDMA) interacts with therapeutic drugs on CYP3A by inhibition of pregnane $X$ receptor (PXR) activation and catalytic enzyme inhibition. Toxicol Lett. 2011; 203(1):82-91.

21. Zhou S, Chan SY, Goh BC, Chan E, Duan W, Huang M, et al. Mechanismbased inhibition of cytochrome P450 3A4 by therapeutic drugs. Clin Pharmacokinet. 2005;44(3):279-304.

22. Farré M, Abanades S, Roset PN, Peiró AM, Torrens M, O'Mathúna B, et al. Pharmacological interaction between 3, 4methylenedioxymethamphetamine (ecstasy) and paroxetine: pharmacological effects and pharmacokinetics. J Pharmacol Exp Ther. 2007; 323(3):954-62

23. Vuori E, Henry JA, Ojanperä I, Nieminen R, Savolainen T, Wahlsten P, et al. Death following ingestion of MDMA (ecstasy) and moclobemide. Addiction. 2003:98(3):365-8.

24. Fetter JC. Letter to the Editor: Mirtazepine for MDMA-induced Depression. Am J Addict. 2005:14(3):300-1.

25. Mohamed WM, Hamida SB, Cassel J-C, de Vasconcelos AP, Jones BC. MDMA: interactions with other psychoactive drugs. Pharmacol Biochem Behav. 2011;99(4):759-74

26. Baumann MH, Rothman RB. Neural and cardiac toxicities associated with 3, 4-methylenedioxymethamphetamine (MDMA). Int Rev Neurobiol. 2009;88: 257-96.

27. Greenblatt DJ, von Moltke LL, Harmatz JS, Shader RI. Human cytochromes and some newer antidepressants: kinetics, metabolism, and drug interactions. J Clin Psychopharmacol. 1999:19(5):23S-35S.

28. Anttila SA, Rasanen I, Leinonen EV. Fluvoxamine augmentation increases serum mirtazapine concentrations three-to fourfold. Ann Pharmacother. 2001;35(10):1221-3.

\section{Submit your next manuscript to BioMed Central and we will help you at every step:}

- We accept pre-submission inquiries

- Our selector tool helps you to find the most relevant journal

- We provide round the clock customer support

- Convenient online submission

- Thorough peer review

- Inclusion in PubMed and all major indexing services

- Maximum visibility for your research

Submit your manuscript at www.biomedcentral.com/submit
Biomed Central 